\title{
QUANDO A CIÊNCIA ENCONTRA A AUTO-ANÁLISE: A HERANÇA DE PIERRE BOURDIEU PARA UMA SOCIOLOGIA DA AUTODEFESA
}

\author{
Alexandre Manzoni ${ }^{1}$
}

\begin{abstract}
Resumo
O presente artigo interpreta o cenário do campo científico no Brasil contemporâneo à luz da teoria sociológica de Pierre Bourdieu. Nesse esforço, se debruça sobre o modo como Bourdieu produz uma teoria das classes, sugerindo que sua sociologia reorganiza o esquema marxiano na questão dos interesses. Reconstitui o modo como Bourdieu faz do habitus um conceito operativo, e aponta em que medida o habitus é cingido pela classe social. Na sequência, opera a análise referente a articulação estabelecida entre a classe e o habitus, evidenciando o quanto essa ligação atua na composição das categorias de percepção de mundo dos agentes. $\mathrm{O}$ artigo elege o conceito de auto-análise coletiva ou socioanálise coletiva de Bourdieu, colocando o campo científico brasileiro sob o crivo analítico. A interpretação elaborada indica que as rearticulações políticas dos últimos anos, em especial das classes médias, resultaram numa fragilização do campo científico brasileiro. Junto a isso, as reformas administrativas e cortes orçamentários do Estado colocam os pesquisadores em situação de conflito pela escassez de recursos. Por fim, o texto relembra algumas saídas produzidas por Pierre Bourdieu no contexto francês, quando a ciência está sob o ataque do neoliberalismo. Isso para fomentar, no horizonte de debates entre pesquisadores e cientistas brasileiros, a possibilidade de esboçar uma sociologia de autodefesa da autonomia do campo científico.
\end{abstract}

Palavras-chave: Pierre Bourdieu. Auto-análise. Ciência. Classe social. Habitus.

\section{When science meets self-analysis: Pierre Bourdieu's heritage for a sociology of self-defense}

\begin{abstract}
This article interprets the scenario of the scientific field in contemporary Brazil in the light of Pierre Bourdieu's sociological theory. In this effort, he looks at how Bourdieu produces a theory of classes, suggesting that his sociology reorganizes the Marxian scheme in the matter of interests. It reconstructs the way in which Bourdieu makes habitus an operative concept, and points out the extent to which habitus is restricted by social class. In the sequence, the analysis regarding the articulation established between the class and the habitus operates, showing how much this connection acts in the composition of the agents' world perception categories. The article chooses Bourdieu's concept of collective self-analysis or collective socio-analysis, placing the Brazilian scientific field under analytical scrutiny. The elaborated interpretation indicates that the political rearticulations of the last years, especially of the middle classes, resulted in a weakening of the Brazilian scientific field. Along with this, the administrative reforms and budget cuts of the State put researchers in a conflict situation due to the scarcity of resources. Finally, the text recalls some outputs produced by Pierre Bourdieu in the French

${ }^{1}$ Licenciado em Ciências Sociais pela Universidade Federal do Rio Grande do Sul. Mestrando pelo Programa de Pós-Graduação em Sociologia (PPGS) da Universidade Federal do Rio Grande do Sul na linha de pesquisa Sociedade e Conhecimento. E-mail: xandy.manzoni@gmail.com. ORCID: https://orcid.org/0000-0002-4610-0678.
\end{abstract}


context, when science is under the attack of neoliberalism. This is to encourage, in the horizon of debates between Brazilian researchers and scientists, the possibility of sketching a sociology of self-defense of the autonomy of the scientific field.

Keywords: Pierre Bourdieu. Self-analysis. Science. Social class. Habitus.

\section{Cuando la ciencia encuentra el autoanálisis: la herencia de Pierre Bourdieu para una sociología de autodefensa}

\section{Resumen}

El presente artículo interpreta el escenario del campo científico en el Brasil contemporáneo a la luz de la teoría sociológica de Pierre Bourdieu. En este esfuerzo, se desenvuelve sobre el modo como Bourdieu produce una teoría de las clases, sugiriendo que su sociología reorganiza el esquema marxista en la relación de los intereses. Reconstituye el modo como Bourdieu hace del habitus un concepto operacional, y apunta en qué medida el habitus es ceñido por la clase social. En la secuencia, trabaja el análisis referente a la articulación establecida entre la clase y el habitus, evidenciando cuánto esta conexión actúa en la composición de las categorías de percepción de mundo de los agentes. El artículo elige el concepto de autoanálisis colectivo o socioanálisis colectivo de Bourdieu, poniendo el campo científico brasilero bajo el cribo analítico. La interpretación elaborada indica que las rearticulaciones políticas de los últimos años, en especial de las clases medias, resultaron en una fragilización del campo científico brasilero. Con ello, las reformas administrativas y los cortes de los presupuestos del Estado colocan a los investigadores en una situación de conflicto por la escasez de recursos. Por fin, el texto recuerda algunas salidas producidas por Pierre Bourdieu en el contexto francés, cuando la ciencia está bajo el ataque del neoliberalismo. Esto para fomentar, en el horizonte de debates entre investigadores y científicos brasileros, la posibilidad de bosquejar una sociología de autodefensa de la autonomía del campo científico.

Palabras llave: Pierre Bourdieu. Autoanálisis. Ciencia. Clase social. Habitus. 


\section{Introdução}

Pierre Bourdieu (1930-2002) nasceu na cidade de Denguin, na França. De origem campesina, filósofo de formação, construiu a maior parte da sua carreira acadêmica como sociólogo, chegando a ocupar o lugar de docente na École de Sociologie du Collège de France, instituição acadêmica mais prestigiada de seu país. No Collège de France Bourdieu foi consagrado como um dos maiores intelectuais do século XX. Filho de um funcionário público de baixo escalão de uma província interiorana francesa, galgou posições no campo científico até atingir o topo da pirâmide na aristocracia intelectual.

Filho único, Bourdieu viveu parte da infância, toda a adolescência e o início da vida adulta entre dois internatos. Primeiro no liceu de Pau entre os anos de 1941 e 1947 e depois no liceu de Louis-leGrand em Paris, entre os anos de 1948 e 1951 (CATANI, 2008). O frio que passou no inverno, a vergonha ao usar o banheiro do internato, as humilhações e reprimendas por parte dos agentes das instituições nas quais conviveu, as inúmeras advertências e suspensões recebidas, a incompreensão dos pais, a falta de amigos pelo estigma de interno, a solidão nas férias, são memórias que marcaram com aflição e tristeza a vida de Bourdieu (CATANI, 2008).

Pela tinta da caneta de seus detratores foi escrita a acusação de que o sociólogo teria contaminado a disciplina acadêmica com os ressentimentos da sofrida trajetória pessoal. As mágoas de Bourdieu, segundo alguns, resultaria num modelo de análise sociológica determinista (THIRY-CHERQUES, 2006). Em sua obra Esboço de autoanálise (2005), Bourdieu descreve as condições de possibilidade do campo universitário da França na sua inserção na década de 1950. Numa situação de desajuste no Khâgne do Liceu Luis-le-Grand, percebendo sua posição dissidente em relação aos herdeiros da filosofia consagrada, postulou que "compreender é primeiro compreender o campo com o qual e contra o qual cada um se faz" (BOURDIEU, 2005, p. 40).

Pierre Bourdieu veria nas condutas de seus colegas, postulantes (ou pretendentes) ao desígnio de filósofos a emanação de um espírito corporativo, cujas corporalidades exteriorizavam a crença de uma "essência superior" (BOURDIEU, 2005).

Produtos puros de uma instituição escolar triunfante, que concedia a sua "elite" um reconhecimento incondicional, transformando, por exemplo, um concurso escolar de recrutamento (a agregação em

CSOnline - Revista Eletrônica de Ciências Sociais, Juiz de Fora, n. 32 (2020). 
filosofia) numa instância de consagração intelectual [...], essas espécies de crianças-prodígios se viam conferir por decreto, aos vinte anos de idade, os privilégios e as obrigações do gênio (BOURDIEU, 2005, p. 57).

Entendendo que participar desse espaço de produção de conhecimento exigia disposições que the eram ausentes, iniciava sua migração da filosofia para o campo da sociologia. Todavia, o impacto de suas experiências faria com que sua teoria se voltasse para a objetivação dos agentes e instituições responsáveis pela produção das classificações legítimas do universo social. Bourdieu passaria a vida orientando seu trabalho por uma feroz desnaturalização dos consensos. Por considerar a sociologia bourdieusiana uma das formas mais radicais de contrassenso, este artigo pretende instigar uma apropriação de sua obra como uma ciência em estado de guerra.

Nesse esforço, nos debruçamos sobre o modo como Bourdieu produz uma teoria das classes, e sugerimos que sua sociologia reorganiza o esquema marxiano na questão dos interesses. Apontamos o quanto Bourdieu faz do habitus um conceito operativo, cingido de forma profunda pela classe social. Operamos uma análise intencionada, cujo desejo se traduz na exposição dos vínculos entre classe e habitus para a composição das categorias de percepção de mundo dos indivíduos.

O artigo elege o conceito de auto-análise coletiva ou socioanálise coletiva para colocar o campo científico brasileiro sob o crivo analítico. A interpretação elaborada indica que as rearticulações políticas dos últimos anos, em especial das classes médias, resultaram numa fragilização do campo científico brasileiro. Junto a isso, as reformas administrativas e cortes orçamentários do Estado colocam os pesquisadores em situação de conflito pela escassez de recursos.

Por fim, o texto relembra algumas saídas produzidas por Pierre Bourdieu no contexto francês, quando a ciência está sob o ataque do neoliberalismo. Isso tudo para fomentar, no horizonte de debates entre pesquisadores e cientistas brasileiros, a possibilidade de esboçar uma sociologia de autodefesa da autonomia do campo científico.

\section{A releitura bourdieusiana: classe, habitus e categorias de percepção}


Em sociologia, são inúmeros os empreendimentos teóricos que buscaram responder sobre a questão das classes perguntas como: o que é uma classe social? Quais elementos a constituem? Como uma classe social se reproduz? A obra de Pierre Bourdieu não foi indiferente ao tema. Associando teoria e pesquisa, o sociólogo elaborou sobre as classes o que, para alguns de seus intérpretes, se traduz no "âmago de seu projeto científico" (WACQUANT, 2013, p. 87).

Comprando a ideia de que sua teoria das classes sociais se desenvolve como uma síntese (WACQUANT, 2013) vemos que de Karl Marx o autor incorpora os aspectos conflitivos presentes em sua análise do modo de produção capitalista (MARX, 2017). De Émile Durkheim, Bourdieu internaliza as representações coletivas (DURKHEIM, 2010) e, da sociologia de Max Weber, a relevância das especificidades culturais para formação econômica de um grupo (WEBER, 2004). Entretanto, pelo fato de Bourdieu enfatizar que as apreciações dos agentes são tributárias de bases objetivas acerca das divisões sociais, sejam elas motivadas por relações de trabalho, disputas políticas ou quaisquer que sejam os termos, entendemos que Marx se constitui como o principal interlocutor de Bourdieu na questão das classes.

Se para Marx o que possibilitava a delimitação de uma classe social era a identidade de renda e/ou fonte de renda dos seus integrantes, vivendo os operários, os capitalistas e os proprietários de terras respectivamente de salário, lucro e renda do solo, ou seja, os primeiros da exploração de sua força de trabalho, os segundos de seu capital e os terceiros de sua propriedade fundiária (MARX, 2017), para Bourdieu, demarcar uma classe social requer $O$ acréscimo das dimensões simbólicas que orientam as práticas de cada grupo social. É assim que Bourdieu elege em seu quadro de análise o corpo vivido não apenas como o lugar de encarnação da história material, mas também como locus de exteriorização dos comportamentos de classe, tornando a sociologia capaz de objetivar o fato de que classe social faz a vida acontecer para além do trabalho.

Uma leitura visceral de $A$ distinção (2007) mostra que a obra mais importante de Bourdieu reorganiza o esquema marxista na questão dos interesses. Em sua análise, o que está em jogo no mundo social são os enfeixes relacionais, considerando tanto aspectos estruturais quanto a agência dos indivíduos. A sociologia bourdieusiana abandona o princípio determinista presente no marxismo de que as 
condições materiais de vida se sobrepõem a todas as condições sociais. Isso se dá a partir do distanciamento de Bourdieu em relação as apreciações feitas por Marx sobre as lutas sociais e reprodução das classes.

No quadro marxiano, as lutas sociais são vistas a partir de uma premissa predatória, em que a luta de classes, numa perspectiva material, engloba todos os conflitos nas mais diversas instâncias da vida. Ao passo que a reprodução das classes se constituiria como um espelhamento imediato entre as condições materiais de existência e a posição social de cada indivíduo. Em Bourdieu, as lutas sociais adquirem dimensões setoriais, que não se vinculam diretamente e/ou principalmente a disputas materiais. Como sugere um dos capítulos de $A$ distinção intitulado $A$ luta contra a desclassificação, estão em disputa nestas lutas os recursos específicos de cada espaço social, que Bourdieu conceitua como Campos.

Os campos se apresentam à apreensão sincrônica como espaços estruturados de posições (ou de postos) cujas propriedades dependem das posições nestes espaços, podendo ser analisadas independentemente das características de seus ocupantes (em parte determinadas por elas). Há leis gerais dos campos: campos tão diferentes como o campo da política, o campo da filosofia, o campo da religião possuem leis de funcionamento invariantes [...]. Cada vez que se estuda um novo campo, seja o campo da filologia no século XIX, da moda atual ou da religião da Idade Média, descobre-se propriedades específicas, próprias a um campo particular, ao mesmo tempo que se faz avançar o conhecimento dos mecanismos universais dos campos que se especificam em função de variáveis secundárias. [...] sabe-se que em cada campo se encontrará uma luta, da qual se deve, cada vez, procurar as formas específicas (BOURDIEU, 1983, p. 89).

Já a reprodução social, para Bourdieu, depende tanto das posições objetivas ocupadas pelos agentes nos campos, quanto de dimensões simbólicas (culturais, políticas, artísticas) presentes nesses espaços, que se autonomizam de uma origem econômica tal qual exposta no esquema marxista. Todavia, cabe salientar que Bourdieu se distancia simultaneamente das compreensões que enxergam na estrutura social o produto de um agregado de vontades e ações individuais, sendo este o motivo pelo qual rechaça a conceituação de classe nos termos weberianos (WACQUANT, 2013).

As classes sociais, para Bourdieu, escapam do determinismo econômico, mas o mesmo não pode ser dito sobre os indivíduos, 
cujas vidas não escapam das determinações impostas pelas classes, considerando a força das visões de mundo por elas produzidas (BOURDIEU, 2004a). O autor entende a classe como um domínio superior em relação a outros marcadores sociais (étnicos, sexuais, religiosos etc.), um domínio capaz de delinear vastas esferas da vida como, por exemplo, o consumo cotidiano, as preferências políticas, a relação com as instituições de ensino (BOURDIEU, 2004a).

Para o sociólogo, o próprio fato de a classe existir como tal e com tal relevância, resulta de um labor, de lutas para determinar a classe como o principal meio de ver e viver, acima de todos os marcadores concorrentes (BOURDIEU, 2004a). A classe, pela sua lente, se faz na carne como uma marca corpórea indelével.

Ao sofisticar o espectro marxiano, o sociólogo vê a classe composta por uma dimensão que inclui os aspectos materiais, tais como propriedades e bens, e outra que versa sobre os estilos de vida e as classificações implicadas pela socialização de classe. Pelos estilos de vida os agentes demonstram sua consciência prática relativa aos gostos de classe (BOURDIEU, 2007). Para Bourdieu, as classes só podem ser constituídas e mantidas como tal a partir da inculcação de categorias de percepção de mundo, convertidas pelos agentes em representações da realidade social (BOURDIEU, 2004a).

Sua sociologia etnográfica se volta para a resolução de problemas concretos originados no campo pesquisado, tais como: as expectativas de sucesso e fracasso escolar nas diferentes classes (BOURDIEU; PASSERON, 2015); a recusa do camponês diante da fotografia abstrata (BOURDIEU, 2011); o gosto alimentar de pobres e ricos (BOURDIEU, 2007); as disputas institucionais entre cientistas (BOURDIEU, 2004b); etc. Por isso, a socioantropologia bourdieusiana se lança a produção de conceitos com os quais possa operar a análise dos problemas construídos no contato com fenômenos tangíveis.

Em seus trabalhos, a classe atua como uma matriz que congrega coletivamente os agentes que dela fazem parte, servindo como princípio de conduta e visão de mundo nas mais diversas instâncias da existência. Nos escritos do autor, o humano figura como um animal simbólico pois, a forma como ele habita e transforma 0 mundo depende de seus sistemas de comunicação, de suas formas de conhecimento (ciência, filosofia etc.) e de suas crenças mitológicas e religiosas - neste último caso se evidencia a influência durkheiminiana acerca dos elementos mágicos do social (DURKHEIM, 1996). 
Em sua teoria empírica, a alquimia entre o social e o simbólico se concretiza no corpo do agente. Na esteira bourdieusiana, toda a interiorização de categorias de percepção produzidas numa classe depende da internalização de um habitus, ou melhor, de um habitus de classe (BOURDIEU, 2004a).

O habitus se constitui como um sistema de disposições (psíquicas e corporais) duráveis e transferiveis, tanto conscientes quanto inconscientes. Atua como elemento gerador de práticas e representações, sendo responsável pela interiorização das estruturas sociais, em que pese a particularidade das formas de existência em cada grupo (BOURDIEU, 2004a). O habitus se refere a um sistema de orientação das convicções, sejam elas latentes ou evidentes, de maneira a estruturar o conjunto dos juízos e ações dos agentes (CICOUREL, 2007).

A definição de habitus bourdieusiana "foi pensada como um expediente para escapar do paradigma objetivista do estruturalismo sem recair na filosofia do sujeito e da consciência" (THIRY-CHERQUES, 2006, p. 33). Por meio do conceito de habitus ele explica como a história individual e coletiva se faz corpo e pensamento tendo em vista dois domínios: primeiro, pelo modo como o corpo se insere em diferentes espaços a partir das condições materiais do indivíduo, seu grau de instrução, sua profissão e origem familiar; segundo, pela forma como são incorporadas as disposições, o senso estético, as categorias de julgamento social etc.

O habitus não é coerente, estático ou único. Refere-se, sobretudo, a um conjunto dinâmico de possibilidades de ação dos agentes, estimulados por esquemas de comportamento adquiridos em todas as experiencias anteriores. Ele se traduz como um gesto ordenado sem ordenamento. Em si mesmo não é determinante, mas rege o indivíduo como um estoque de condicionantes de relevâncias distintas, acionado à revelia de qualquer reflexão prévia.

Desconsiderando o habitus como determinante, devido a multiplicidade de disposições que o compõe, Bourdieu elege o conceito de agente ao invés do conceito de sujeito para se referir aos indivíduos (THIRY-CHERQUES, 2006). Pois, na medida em que estes atuam a partir do senso prático e das categorias de percepção, internalizam novas disposições, já que os efeitos da ação se submetem ao tempo e ao espaço. Significa dizer que na ação dos indivíduos, o habitus exerce a exteriorização da 
interioridade, retornando ao agente na forma de reestruturação das disposições (BOURDIEU, 2004a).

O habitus se manifesta em diferentes gradações, em conformidade com a intensidade pela qual cada parte da sociedade foi depositada no indivíduo (WACQUANT, 2007). No percurso de um ator social, cada constrangimento e exigência de uma ação especifica funcionam como uma forma de treinamento corporal e psicológico incessante, desaguando nas formas de ser, sentir e agir de cada pessoa (BOURDIEU, 2002). O habitus se manifesta como uma segunda natureza pois, se trata de uma condição sociohistórica interiorizado de modo inconsciente (THIRY-CHERQUES, 2006).

No limite, o habitus rege as condutas com liberação ou censura, levando em conta os princípios que orientam a classe de origem dos atores. Esse mecanismo é responsável pelo modo como os currículos de vida passam a ser desejáveis ou indesejáveis em cada grupo social, produzindo a ilusão da escolha pessoal e, ao mesmo tempo, as distinções pelo habitus cujo valor da escolha consagra (BOURDIEU, 2007). O sociólogo aponta que, em geral, os agentes das diversas classes não têm como objeto de desejo experiências radicalmente destoantes daquelas vividas na trajetória pessoal ou pelos integrantes da mesma classe (BOURDIEU, 2007). Pensando o habitus como elemento de classe, significa dizer que:

[...] conjuntos de agentes que ocupam posições semelhantes e que, colocados em condições semelhantes e sujeitos a condicionamentos semelhantes, têm, com toda a probabilidade, atitudes e interesses semelhantes, logo, práticas e tomadas de posição semelhantes (BOURDIEU, 2004a, p. 136).

A partir do habitus aprendemos os signos da linguagem, adquirimos apreço pela leitura, temos preferência por determinado estilo musical, militamos em defesa de uma narrativa sobre o mundo (científica, religiosa, filosófica etc.). Por seu intermédio, o mundo se apresenta aos indivíduos, é ele quem acomoda as influências sociais, seja na performance corporal, na conduta moral ou nas formas de consumo (BOURDIEU, 2004a).

Embora seja um conceito e, como tal, carregado de dimensões abstratas, ele foi a forma encontrada por Bourdieu para nomear o processo inconsciente pelo qual os indivíduos regem o cotidiano em estado prático. Seja pelas posturas que assumimos nos diferentes ambientes, por expressões faciais que indicam nossos 
estados emocionais, pelas habilidades corporais que adquirimos numa atividade física, ou pela nossa capacidade intelectual de internalizar o mundo social a partir de classificações objetivas.

O habitus faz com que coletividades compartilhem um conjunto de crenças mais ou menos coesas para produzir o que chamamos de "realidade" (BOURDIEU, 2001). É pela retenção do habitus como uma herança social profunda, que Bourdieu reformula o problema implicado na dominação de classes, ao pôr em xeque o substrato ontológico que rege a modernidade sob a batuta burguesa (BOURDIEU, 2007).

Quando lemos Bourdieu precisamos ter em mente que sua sociologia é uma Sociologia do Conhecimento. E como tal, interroga a repercussão dos sentidos emanados a partir das categorias produzidas por uma determinada base social. Pergunta básica desta disciplina se daria nos seguintes termos: por que pensamos da forma como pensamos e agimos do modo como agimos?

Um retorno a análise praxiológica das classes elaborada por Bourdieu dá conta de que, no núcleo da sua sociologia, ele desenvolve a apreciação de que os esquemas mentais inculcados numa sociedade, nesse caso uma sociedade burguesa, se solidificam como realidades históricas que duram no tempo na forma de instituições e disposições, capazes de circular socialmente por meio de sistemas simbólicos. É por isso que a sua teoria da prática está voltada para a objetivação dos agentes classificadores, os produtores das dimensões simbólicas, responsáveis pela produção das categorias pelas quais as classes pensam e veem.

Na análise dos sentidos das categorias ele realiza uma análise histórica da conformação desses sentidos. Responde a questões de fundo como: qual a origem dessas categorias? Quais seus remanescentes? Em que contexto passaram a ser produzidas? Possibilitando ao conjunto da sua obra a apreensão da multiplicidade de sentidos realizados pelo trabalho de categorização, e as repercussões provocadas por esse labor na constituição de estruturas simbólicas de poder.

Façamos o quadro analítico bourdieusiano falar por meio de um exemplo. Sabemos que nas sociedades ocidentais comumente as pessoas acreditam em coisas como "representatividade política". Discutir o conjunto dos fundamentos ontológicos de uma 
sociedade burguesa, na qual se acredita em coisas como "representatividade política", nos coloca diante de uma estrutura social que aceita um conjunto de máximas do tipo: o poder pode ser representado; existe uma relação estreita entre eleitor e eleito; o eleito, autorizado por um conjunto de poderes, representa os interesses de seus eleitores. Poderíamos estabelecer diálogo com esses enunciados a partir de um conceito de "democracia" bastante limitado, em que cada eleitor, tendo direito ao voto, seria mais ou menos livre para optar por uma entre as visões de mundo concorrentes.

Na perspectiva bourdieusiana, não devemos assumir os princípios normativos de uma representação originada pelo voto pois, corremos o risco do voluntarismo com a amnésia da gênese pela qual esse modelo político hegemoniza a visão de mundo das classes dominadas como sinônimo de democracia. Assumir tal postura significa jogar o jogo na visão de mundo dominante, se valendo das categorias (representatividade, democracia etc.) elaboradas para manter o status de determinados grupos.

As categorias de percepção do mundo social são, no essencial, produto da incorporação das estruturas objetivas do espaço social. Em consequência, levam os agentes a tomarem o mundo social tal como ele é, a aceitarem-no como natural, mais do que a rebelaremse contra ele, a oporem-lhe possíveis diferentes, e até mesmo antagonistas: o sentido da posição como sentido daquilo que se pode ou se não pode "permitir-se a si mesmo", implica uma aceitação tácita da posição, um sentido dos limites ("isso não é para nós") ou, o que é a mesma coisa, um sentido das distâncias, a marcar e a sustentar, a respeitar e a fazer respeitar - e isto, sem dúvida, de modo tanto mais firme quanto mais rigorosas são as condições de existência e quanto mais rigorosa é a imposição do princípio de realidade (daí o profundo realismo que caracteriza frequentemente a visão do mundo dos dominados e que, funcionando como uma espécie de instinto de conservação socialmente constituído, só pode parecer conservador em referência a uma representação exterior, portanto normativa, do "interesse objetivo" daqueles que ele ajuda a viver ou a sobreviver) (BOURDIEU, 2004a, p. 141).

É por isso que Bourdieu vai chamar a sociologia de um esporte de combate pois, em sociologia não se discute a partir da narrativa normativa, a arma do sociólogo é justamente olhar por trás da máquina de produção de enunciados e mostrar que aquilo que está subjacente a um conjunto de máximas são recursos. Por trás dos enunciados, dos discursos, está o dinheiro, o prestígio, a 
autoridade, a consagração. É vida e morte que está por trás das categorias dominantes produzidas pelos juízos dos julgadores.

[...] este trabalho de categorização, quer dizer, de explicitação e de classificação, faz-se sem interrupção, a cada momento da existência corrente, a propósito das lutas que opõem os agentes acerca do sentido do mundo social e da sua posição nesse mundo, da sua identidade social, por meio de todas as formas do bem dizer e do mal dizer, da bendição ou da maldição e da maledicência, elogios, congratulações, louvores, cumprimentos ou insultos, censuras, críticas, acusações, calúnias, etc. (BOURDIEU, 2004a, p. 142).

O produto dessa análise nos induziria a dizer que as ideias encarnadas pelos agentes se articulam a seus interesses particulares. Contudo, as ideias internalizadas e as maneiras de agir não são necessariamente conscientes dirá Bourdieu. Portanto, o que existe por baixo da casca, quando aplicamos o quadro de análise bourdieusiano, é mais do que interesses particulares. Há uma crença coletiva de que o voto na figura do eleito se traduz na representação do conjunto de interesses de todos os seus eleitores. Isso evidencia uma metafisica subjacente ao modo como a crença é produzida. Poderíamos dizer que esse é um modo de religião ocidental, uma forma de magia política, em que interesses tão diversos se cristalizam na figura do eleito.

Quando fazemos sociologia ao modo de Bourdieu, questionamos mais do que as dimensões individuais dos interesses. Ao observarmos o status ontológico de uma sociedade deixamos de particularizar, e nos dando conta de que existem bases metafísicas implícitas, que fazem com que as pessoas acreditem num conjunto de aparatos conceituais. Porque, na articulação dessas categorias provenientes de uma determinada sociedade, não apenas as pessoas dão sentido a suas vidas, como as classes orientam seus comportamentos pelos signos sociais que elegem como sagrados.

\section{Em defesa do campo científico}

Diante do plano de austeridade brasileiro que chega as universidades com as reduções de verbas às instituições de 
fomento à pesquisa como a $\mathrm{CAPES}^{2}$ e o $\mathrm{CNPq}^{3}$, articulamos a teoria bourdieusiana para repensarmos enquanto cientistas as nossas experiências e o futuro das instituições acadêmicas no Brasil. Para isso, fazemos uso de um conceito chave de Bourdieu, o conceito de auto-análise coletiva ou socioanálise coletiva. A partir desse conceito perguntamos: como analisar o momento de fragilidade e contestação da ciência? Em especial da sociologia e demais ciências humanas no Brasil.

Em Os usos sociais da ciência (2004b), Bourdieu elabora um discurso para uma instituição de pesquisa francesa, o INRA. Essa instituição tem de um lado um conjunto de pesquisadores que fazem a pesquisa dita "pura", cujo trabalho não possui relação com aquilo que é exigido pelo mercado (BOURDIEU, 2004b). De outro lado, há um conjunto de pesquisadores que fazem a pesquisa denominada "aplicada", voltada para questões práticas, metodicamente generalizáveis, que não precisam analisar fundamentos epistêmicos (BOURDIEU, 2004b).

O conceito de auto-análise bourdieusiano traduz o que sua teoria acrescenta a epistemologia bachelardiana da qual é herdeiro, a ideia de que as dimensões epistêmicas da ciência dependem de uma socioanálise coletiva dos espaços de produção cientifica. Ele mostra que o campo científico precisa ser analisado sociologicamente (BOURDIEU; CHAMBOREDON, PASSERON, 2010), não se trata de um avanço em termos epistemológicos, o que as instituições de produção científica precisam para produzir ciência é de autonomia (BOURDIEU, 2004b).

O que isso significa no Brasil contemporâneo? Significa que as instituições científicas terão sua autonomia defasada, sobretudo as ciências "puras". Remontando o discurso do sociólogo ao INRA podemos compreender a gravidade da situação brasileira. A obra aponta que a dinâmica da ideologia no interior do campo científico reforça a manutenção de uma ortodoxia, e o que acontece nas instituições acadêmicas quando os recursos são escassos é uma relação de conflito entre os cientistas (BOURDIEU, 2001, 2004b). Aqueles que fazem pesquisa aplicada se consideram

\footnotetext{
${ }^{2}$ CARVALHO, Letícia. Capes corta 5.613 bolsas a partir deste mês e prevê economia de R\$ 544 milhões em 4 anos. G1, São Paulo, 2 de set. de 2019. Disponível em: $<$ https://g1.globo.com/educacao/noticia/2019/09/02/capes-deixa-de-oferecer-5613-bolsas-apartir-deste-mes-e-preve-economia-de-r-544-milhoes-em-4-anos.ghtml>. Acesso em: 30 de set. de 2020.

${ }^{3}$ ESCOBAR, Herton. CNPQ diz que não terá verba para investir em pesquisa em 2019. Estadão, São Paulo, 9 de ago. de 2018. Disponível em: < https://ciencia.estadao.com.br/noticias/geral,cnpq-dizque-so-tera-verba-para-bolsas-em-2019,70002438970>. Acesso em: 30 de set. de 2020.
}

CSOnline - Revista Eletrônica de Ciências Sociais, Juiz de Fora, n. 32 (2020). 
os sujeitos produtivos, enquanto os que trabalham com pesquisa pura se arrogam como os verdadeiros cientistas (BOURDIEU, 2004b).

O cientista ortodoxo tem um sentido do jogo mais adequado para uma disputa em âmbito institucional, possui maiores chances de continuar fazendo ciência. Especialmente quando a ciência é contestada, considerando que esse cientista faz pesquisas sob a ordem estabelecida, faz a ciência dita "normal" (BOURDIEU, 2004b). Esse pesquisador se dedica a aplicação de um conjunto de métodos, não questiona as categorias em jogo, trabalha com aplicação do que já está consagrado. Seu ofício é pôr em movimento a máquina de produção de enunciados e evidências científicas reconhecidas, não 0 de questionar problemas epistêmicos subjacentes.

Em contrapartida, o cientista mais transgressor, que passa anos decompondo dimensões ideológicas implícitas, questões de fundo ontológicas, filosóficas e epistemológicas, terá de enfrentar o estigma de quem não produz nada útil. Não produz coisas que se conectam com demandas sociais e de mercado e, portanto, não aglutina rendimentos. Ao mesmo tempo, esse cientista prolifera objetos científicos complexos, na medida em que não vincula seu esforço imediatamente a demandas. Produz inúmeras renovações, mas restritas a pequenos grupos de já iniciados na sua disciplina (BOURDIEU, 2004b).

Podemos perguntar, a partir disso, quem recebe recursos para fazer pesquisas num cenário de escassez. Dificilmente são aqueles que fazem pesquisas transformadoras, no geral, são aqueles que relacionam sua pesquisa com os interesses externos ao campo científico.

\footnotetext{
O paradoxo dos campos científicos, entretanto, é que eles produzem, ao mesmo tempo, essas pulsões destrutivas e o controle dessas pulsões. Se você deseja triunfar sobre um matemático, é preciso fazêlo matematicamente pela demonstração ou refutação. Evidentemente, há sempre a possibilidade de que o soldado romano corte a cabeça de um matemático, mas isso é um "erro de categoria", diriam os filósofos. Pascal veria nisso um ato de tirania que consiste em utilizar numa ordem um poder que pertence a outra ordem (BOURDIEU, 2004b, p. 32).
}

As lógicas de produção exteriores ao espaço científico dialogam melhor com os indivíduos que fazem pesquisa aplicada se comparados com aqueles que pesquisam objetos estritos à ciência. Portanto, quem recebe recursos em momentos de retração de 
gastos são os pesquisadores ortodoxos, pelas afinidades que possuem com as exigências externas ao campo como, por exemplo, a produção de pesquisas eleitorais ou de políticas públicas.

Aos herdeiros da ciência normal é confiada a manutenção do paradigma científico e, reciprocamente, os herdeiros dessa ciência confiam no paradigma (BOURDIEU; PASSERON, 2015). Estes cientistas corrigem as lacunas das teorias dominantes de modo a fazê-las funcionar normalmente, são administradores científicos, fazem a ciência normal e estão propensos a identificar as inconsistências do paradigma que professam (BOURDIEU; PASSERON, 2015). Em contrapartida, aqueles que ingressam na ciência como não herdeiros, nas condições de desajuste com a norma científica, questionam a maneira pela qual os herdeiros protegem um objeto canônico (BOURDIEU, 2001).

Há um esforço de desnaturalização por parte daqueles que não herdam a episteme dominante, que chegam de fora e não se ajustam a uma tradição de pensamento (BOURDIEU; PASSERON, 2015). Os "estrangeiros" percebem que os fatos científicos eleitos como significativos não são todos, nem os principais fatos que podem dar sentido a uma interpretação (BOURDIEU, 2001). Esses indivíduos denunciam o que os herdeiros não enxergam, o fato de que existem elementos de distorção ontológica nas perspectivas sobre a "realidade" construídas desde as narrativas científicas. A tendência é de que vejam nas exclusões acerca de um sem número de questões, tão ou mais importantes quanto aquelas mobilizadas pelo investimento metódico, a intenção de manter uma visão de mundo hegemônica (BOURDIEU, 2001).

O que está em jogo para os herdeiros é a manutenção de uma ortodoxia, eles são os guardiões da chave mestra, os gramáticos da ordem que consertam as deformidades teóricas de modo a evitar a destruição de uma doxa (BOURDIEU, 2001, 2007). A vocação do herdeiro é o sacerdócio, ele protege numa luta de vida ou morte a conservação do paradigma, porque isso permite exigir dos participantes da illusio do campo que interpretem o "livro sagrado" como sempre se interpretou (BOURDIEU, 2001). Isso é o que faz com que a Bíblia positivista ou o Alcorão funcionalista continuem sendo lidos como de costume (BOURDIEU, 2001).

Em Meditações Pascalianas (2001), Bourdieu nos mostra que a geração de maio de 1968, encarnada por figuras como Michel Foucault, Jacques Derrida e Gilles Deleuze, levou o pensamento 
francês a uma transformação radical que impactou o campo intelectual no mundo. Tratava-se de uma série de pensadores "exóticos", que chegavam na academia francesa (dadas as proporções) num momento correlato ao do Brasil no implemento das políticas de cotas.

Isso indicava a expansão das possibilidades de o campo científico e filosófico absorver grupos marginais, com perfis distintos dos herdeiros. Portanto, um grupo de estranhos, em desavença aos padrões de produção de conhecimento, elaborou desde a França uma revolução no pensamento ocidental moderno, e Bourdieu analisa o fato para mostrar a relação conflituosa entre os pesquisadores no campo científico (BOURDIEU, 2001).

Bourdieu nos coloca diante do fato de que os sujeitos excêntricos profanam as formas dominantes de fazer ciência, e quanto maior o número de indivíduos com biografias dissonantes mais profundas e radicais são as articulações coletivas de traição do paradigma, na tentativa dos desajustados em utilizar as brechas do objeto consagrado para destruí-lo (BOURDIEU, 2001). O que acontece com os herdeiros quando o campo científico é habitado por pensadores marginais é que eles precisam se adequar as mudanças ocorridas no modo de produção da ciência, tendo em vista o esboroamento do paradigma dominante.

Se levarmos a cabo a análise sugerida por Bourdieu, percebemos que as políticas de ações afirmativas atingiram a estrutura de reprodução das classes médias no Brasil. Até o momento das políticas de cotas, a estrutura acadêmica brasileira era o lugar de "eleição dos eleitos" (BOURDIEU, 2005), lugar de distribuição dos diplomas que permitiam a essas classes a sua preservação material, estética e moral como classes distintas (BOURDIEU, 2007).

Ao ingressarem grupos cuja composição racial e de classe destoava do habitual padrão dos herdeiros, uma relação guerreira se evidenciou. A análise bourdieusiana reorganiza o materialismo marxiano, mas mantêm seu sentido no que diz respeito ao conflito. Se torna indispensável perceber que, solapado um interesse de classe, a retaliação por parte do grupo cuja ofensa atingiu é inescapável e, portanto, a ciência como um todo precisava se blindar da vingança, do retorno do recalcado (BOURDIEU, 2005).

Desconsiderando os fatos, muitos acadêmicos acreditam que as universidades estão sob o consenso de que são o lugar de desenvolvimento da ciência, e que todos reconhecem as 
instituições científicas como lugar de produção de conhecimento. Revela-se, no entanto, imprudente pensar o campo científico pela concepção do que seja a ciência, porque a definição de ciência aos olhos do cientista carrega dimensões idealistas. Muitos cientistas esperam que as pessoas vejam a ciência como uma forma de conhecimento sofisticada, entretanto, para quem está fora do campo a ciência vale o que traz de retorno imediato e material, sendo antes um lazer escolástico intrigante e incompreensivel do que uma forma de conhecer (BOURDIEU, 2001).

Todavia, para as classes médias brasileiras, as instituições universitárias sempre foram um meio de legitimação, via diploma, para obterem boas remunerações e cargos de prestígio, afinal de contas, essa é a "República dos bacharéis". Outra parte da tragédia é que o pensamento de senso comum, leigo ou erudito, enxerga as classes sociais por um recorte de renda.

Portanto, muitos cientistas brasileiros, mesmo aqueles que habitam as disciplinas sociológicas, consideraram a diminuição das desigualdades de renda no Brasil como uma forma de ascensão das classes baixas ao status de "classe média". Abstraíram o fato de que classe se faz de berço, numa socialização específica, por determinada cosmologia, com certa expectativa e com um tipo de gosto que a distingue das demais classes (BOURDIEU, 2007).

O que precisa ser discutido não é o quanto as classes baixas consomem, mas como é a luta para se impor como classe superior, que expressa no estilo de vida dos seus integrantes a majestade da diferença. Distinção é consagração, é existência encarnada numa identidade social sublimada (BOURDIEU, 2007). A modernidade, segundo Bourdieu, é regida por uma lógica em que os indivíduos, sobretudo nas classes médias, se pensam por um princípio de existência que valoriza a distinção (BOURDIEU, 2007). A distinção é a justificação das existências humanas em sociedades burguesas, cuja razão de ser não existe em princípio (BOURDIEU, 1988).

A distinção consagra aquele que se diferencia não porque ele acumula mais economicamente que o outro, mesmo nos termos de uma sociedade estratificada em classes. Mas porque este, e não aquele, expressa simbolicamente pela forma de seu consumo material e imaterial a singularização individual ou coletiva em termos morais e estéticos (BOURDIEU, 2007). O que o processo de integração dos grupos minoritários no campo científico aleijou foi a concentração da ciência nas mãos das classes médias, colocando em risco o monopólio da distinção. 
As cotas agrediram 0 núcleo de produção de evidências fantasmáticas do quanto as classes médias são superiores no plano intelectual e estético. Desvalorizou seus títulos de nobreza comportamental e humana expressados pela corporalidade e pensamento, internalizados pelos habitus de classe e científico (BOURDIEU, 2007). Por este motivo, as classes médias brasileiras ressentidas encarnaram uma corporalidade ultrarreacionária, militando em voga de um governo capaz de restituir suas categorias de percepção de mundo pela restrição ao acesso dos "outros" nas instituições de consagração.

Aplicar a auto-análise ao campo científico nos coloca diante do fato de que os cientistas, ao invés de pensarem a dinâmica pela qual a estrutura acadêmica reproduz a cosmovisão de grupos específicos, se envolvem em disputas pela legitimidade entre a ciência pura e a ciência aplicada. Investem seu tempo em contendas metodológicas superficiais, abstraindo as dimensões políticas de institucionalização epistêmica.

Bourdieu sugere que tanto os cientistas inovadores, geralmente vinculados a pesquisa pura, quanto os cientistas ortodoxos, voltados a pesquisa aplicada, são indispensáveis. Os primeiros pelo fato de pensarem questões de fundo, capazes de armar o conjunto das ciências contra os impasses do campo de pesquisa, e os segundos porque suas articulações externas permitem uma defesa política do campo científico (BOURDIEU, 2004b).

Uma interrogação de Bourdieu bastante justa é sobre quem pode financiar o processo de fazer científico. Em sua perspectiva, não pode ser o mercado, considerando que ele restringe a autonomia do campo pelas demandas. Ciência exige autonomia para suas condições de produção, portanto, o Estado deve financiar a ciência, tendo em vista os diferentes fundamentos que orientam 0 público e o privado (BOURDIEU, 1998, 2004b).

Entretanto, na atual conjuntura, teremos de lidar com o fato de que - Estado brasileiro foi sequestrado pelas forças obscuras do neoliberalismo. E que os grupos de pesquisa são pressionados a atender os interesses do setor privado. Dentre outras coisas, o que o neoliberalismo destrói no seu processo predatório é a autonomia do campo científico, e Bourdieu também tem contribuições para pensarmos táticas para enfrentar a invasão neoliberal (BOURDIEU, 1998). 
Em Contrafogos (1998), Bourdieu tenta estabelecer diálogo com movimentos sociais e demais setores dependentes do Estado, não para fazer uma militância científica vulgar, mas porque percebe que as forças nefastas que destroem a ciência são as mesmas que precarizam toda a estrutura social, desde o acesso a consumos básicos pelas classes populares até a esfera das relações pessoais. Em vista disso, recomenda que a ciência, principalmente a sociologia, se articule politicamente para defender a autonomia do campo (BOURDIEU, 1998). Embora sua análise esteja localizada numa realidade sociohistórica distinta, em relação a dinâmica do campo científico, nos parece apropriado articular seus conceitos em defesa da ciência brasileira num momento de obscurantismo.

\section{Considerações finais}

Em vista do exposto, consideramos que a sociologia e as demais ciências humanas no Brasil precisam reconhecer que seus trabalhos estão sob um estado de conflito permanente, por disputas tanto em relação ao Estado quanto em relação ao mercado. É indispensável a solidificação de uma ciência capaz de se manter autônoma à revelia de qualquer governo, mas para isso, o primeiro passo do campo científico é observar como as distintas classes sociais se valem da ciência.

O que sugerimos ao campo científico brasileiro é uma socioanálise coletiva que permita a manutenção das condições de autonomia e das trajetórias dissonantes. Uma defesa das múltiplas formas de fazer ciência, de modo que nenhuma pesquisa sem retorno imediato seja considerada inepta, não diz respeito apenas àqueles pesquisadores cujo objeto não dialoga com setores externos ao campo, se refere a uma defesa da ciência de modo geral. Aqui faz brilhar a atualidade da teoria bourdieusiana, que nos provoca a constituir uma sociologia da autodefesa do campo científico.

\section{Referências}

BOURDIEU, Pierre. A distinção: crítica social do julgamento. Porto Alegre: Zouk, 2007.

BOURDIEU, Pierre. Contrafogos: táticas para enfrentar a invasão neoliberal. Rio de Janeiro: Zahar, 1998.

BOURDIEU, Pierre. Esboço de auto-análise. São Paulo: Companhia das Letras, 2005. 
BOURDIEU, Pierre. Esboço de uma teoria da prática: precedido de três estudos de etnologia Cabila. Oeiras: Celta, 2002.

BOURDIEU, Pierre. Lições da aula. São Paulo: Ática, 1988.

BOURDIEU, Pierre. Meditações pascalianas. Rio de Janeiro: Bertrand Brasil, 2001. BOURDIEU, Pierre. O poder simbólico. Rio de Janeiro: Bertrand Brasil, 2004a. BOURDIEU, Pierre. Os usos sociais da ciência: para uma sociologia clínica do campo científico. São Paulo: Ed. Unesp, 2004b.

BOURDIEU, Pierre. Questões de sociologia. Rio de Janeiro: Marco Zero, 1983.

BOURDIEU, Pierre. Razões práticas: sobre a teoria da ação. Campinas: Papirus, 2011.

BOURDIEU, Pierre; CHAMBOREDON, Jean-Claude; PASSERON, Jean-Claude. Ofício de sociólogo: metodologia da pesquisa na sociologia. Petrópolis: Vozes, 2010.

BOURDIEU, Pierre; PASSERON, Jean-Claude. Os herdeiros: os estudantes e a cultura. Trad. Ione Ribeiro Valle e Nilton Valle. Florianópolis: Ed. Ufsc, 2015.

CARVALHO, Letícia. Capes corta 5.613 bolsas a partir deste mês e prevê economia de R\$544 milhões em 4 anos. G1, São Paulo, 2 de set. de 2019. Disponível em: <https:/g1.globo.com/educacao/noticia/2019/09/02/capesdeixa-de-oferecer-5613-bolsas-a-partir-deste-mes-e-preve-economia-de-r544-milhoes-em-4-anos.ghtml>. Acesso em: 30 de set. de 2020.

CATANI, Afrânio Mendes. Pierre Bourdieu e seu esboço de auto-análise. Eccos Revista Científica, vol. 10, p. 45-65 jul., 2008.

CICOUREL, Aaron V. As manifestações institucionais e cotidianas do habitus. Tempo Soc., São Paulo, v. 19, n. 1, p. 169-188, jun. 2007.

DURKHEIM, Émile. As formas elementares da vida religiosa: o sistema totêmico na Austrália. São Paulo: Martins Fontes, 1996.

DURKHEIM, Émile. Da divisão do trabalho social. São Paulo: Martins Fontes, 2010.

ESCOBAR, Herton. CNPQ diz que não terá verba para investir em pesquisa em 2019. Estadão, São Paulo, 9 de ago. de 2018. Disponível em:

<https://ciencia.estadao.com.br/noticias/geral,cnpq-diz-que-so-tera-verbapara-bolsas-em-2019,70002438970>. Acesso em: 30 de set. de 2020.

MARX, Karl. O capital: crítica da economia política. $2^{a}$ ed. São Paulo: Boitempo, vol. 1, 2017.

THIRY-CHERQUES, Hermano Roberto. Pierre Bourdieu: a teoria na prática. Rev.

Adm. Pública, Rio de Janeiro, v. 40 n. 1, p. 27-53, fev., 2006.

WACQUANT, Loïc. Esclarecer o habitus. Educação \& Linguagem, São Paulo, v. 10, n. 16, p. 63-71, jul., 2007.

WACQUANT, Loïc. Poder simbólico e fabricação de grupos: como Bourdieu reformula a questão das classes. Novos estud. CEBRAP, São Paulo, n.96, p. 87103, jul., 2013.

WEBER, Max. Economia e sociedade: fundamentos da sociologia compreensiva. Brasília: Ed. Unb, 2004.

CSOnline - Revista Eletrônica de Ciências Sociais, Juiz de Fora, n. 32 (2020). 